\title{
Research and Practice on Continuous Learning of Engineering Drawing Course
}

\author{
Shaoni Sun, Ying Huang, Mingxu Ma, Ying Liu
}

School of Mechanical Engineering and Automation, Northeastern University, Shenyang, Liaoning, China (shnisun@me.neu.edu.cn)

Abstract - In order to solve the problems of high knowledge forgetting rate and less continuous use in engineering drawing course for college engineering students, a continuous learning implementation way "learning through racing" is put forward to continue classroom learning, and the practical continuous learning modes for engineering drawing course are developed. Taking advanced drawing contest as an opportunity, the platform of knowledge continuity and ability raise for the students is established. After series of practices such as giving graphics lectures, carrying on rapid drawing training and setting up long-term competitive "collaborative learning" mechanism, students can well master advanced drawing skills and develop innovation design ability. Practice shows that "learning through racing" is a good way to reserve talents for the discipline competitions, innovation projects and researches in university.

Keywords - engineering drawing, graphics education, continuous learning

\section{工程制图课程连续性学习的研究与实践}

\author{
孙少妮 黄英 马明旭 刘荣 \\ 东北大学机械工程与自动化学院, 沈阳, 辽宁, 中国
}

摘 要 针对高等学校工科专业学生在工程制图课程结束后, 课程知识遗忘率高、连续运用性差方面的问题, 提出 “以赛促学” 这 一延续课堂学习的连续性学习实施方式, 从理论和实践两方面研究了工程制图课程连续性学习的重要性及具体的可操作方式。以参加 高水平先进成图竞赛为契机, 通过制定参赛目标、训练计划, 研发快速成图训练模块, 建设长期竞争性 “协同学习” 模式等实践操作 方式, 为学生建立连续性的知识运用与能力提高平台, 使学生熟练运用制图知识的能力提升为先进成图技能和创新设计能力, 为学科 竞赛、创新项目和课题研究储备人才。

关键词 工程制图, 图学教育, 连续性学习

\section{1. 引言}

工程制图课程是工科院校一门重要的技术基础课。课 程内容体系中的工程图模块涉及典型零件、常用零件及标 准件, 与工程实际联系紧密, 有着丰富、直接的工程背景。 然而, 大一学生缺乏实践经验, 给课程学习带来很大困难。 同时, 由于课程设置及学生自身等种种原因, 大一开设的 艰涩课程在大学四年中未得到连续的应用及巩固, 而只在 大四毕业设计中加以使用, 因此, 毕业设计学生的制图知 识与技能一直为专业课教师所诟病。

另一方面, 计算机绘图能力及三维建模能力已成为当 前企业吸纳毕业生所要求基本能力的重要组成部分; 以三 维建模为基础的创新设计能力受到越来越多的重视。然而,
在传统制图课程中, 多以理论知识+尺规绘图的形式为主, 计算机绘图能力及三维建模能力常处于辅助教学地位, 甚 至学时紧张时为保证基本教学任务惨遭缩减。

上述问题都是工程制图课程面临的新挑战, 给本课程 的改革与建设提出了严峻的考验, 同时也为图学教育改革 提供了良好的契机。

通过近年来的教改实践, 提炼出 “以赛促学” 这一延 续课堂学习的连续性学习新模式, 为学生的知识运用与能 力提高提供平台。通过该平台的训练, 学生的工程图读图 能力、三维建模能力和机械零件的构形能力大大提高, 培 养出一批具备优秀先进成图技能和创新设计能力的优秀人 才。 


\section{2. 连续性学习的理论研究}

根据多年的工程制图基础课教学实践以及专业教师对 于学生毕业设计中本课程知识运用情况的反馈, 我们通过 分析认识到高年级学生不能熟练应用制图知识进行毕业设 计的主要原因在于: 学生本科阶段的课程设置并未体现出 对工程制图知识连续性学习的考虑, 因此, 对学生来说, 工程制图这门课只停留在低年级学习的制图基本知识, 而 并没有通过逐渐深入的学习和不断应用使其成为一种技 能。再加上学生自身的各种原因, 大一学习的制图知识未 得到连续的应用及巩固, 因而大四毕业设计中用到时方见 错漏百出。另外, 很多学生本科毕业后直接走上工作岗位 从事设计工作, 对其创新设计能力的要求较高, 有的企业 甚至把学生能够进行三维造型设计、二维工程图绘制等作 为其基本能力。由此可见, 工程制图课程从大一到大四的 连续性学习极为重要, 即使学生课程设置中未加体现, 作 为制图课教师来说也有为学生创造连续学习的必要性。

任何知识都是通过不断学习、不断遗忘、再学习、再 遗忘……这样的规律获取的。知识, 只有通过不断地运用, 才能转化为一定的技能, 从而终身不忘。工程制图课程的 主要任务是培养学生掌握通过工程图样表达和理解设计对 象信息的理论和方法, 同时使学生的空间思维能力得到锻 炼和提高, 为进一步的理论学习和设计实践打下基础。只 有在实践中不断地运用这些制图知识和国家标准的规定, 达到一定熟练度后, 便成为自身技能, 不会遗忘。

结合本科生的学习特点, 发挥工程制图教师自身优势, 制定了保证其进行工程制图课程连续性学习的 “以赛促学” 具体实施方式, 帮助学生规划课程学习计划和愿景, 使学 生对本课程的连续学习有了可实际操作的依据。

大一期间, 以教师主导的课堂教学为主, 主要训练尺 规绘图基本技能, 为课程后续学习打下良好的基础。大二 期间, 以参加高水平的 “高教杯” 全国大学生先进成图技 能竞赛为契机, 选拔学习有余力的学生, 由指导教师对学 生进行辅导, 利用假期进行技能类知识强化和训练, 最终 参加国赛。大三以后, 通过参加各种创新项目, 继续提高 先进成图技能。大四毕业设计中方可游刃有余。

通过 “以赛促学” 方式促进连续性学习的系列活动, 学生的工程图读图能力、三维建模能力和机械零件的构形 能力等各项能力大大提高, 熟练掌握了工业产品的表达方 法和计算机绘图软件的应用。几年来许多参加过三维建模 竞赛的学生表示, 他们在这项活动中受益匪浅, 无论是知 识的学习, 还是能力的锻炼, 都为后来的学习奠定了良好 的基础。

\section{3. 工程制图课程连续性学习实践}

3.1 打造教师主导、学生参与实时调整的一系列选拔机制和 训练计划

在学习工程制图课程基础上, 以校级先进成图技能竞 赛为契机, 选拔出校赛优胜者, 先后利用寒假进行 “以老 带新” 的三维造型软件学习活动, 利用暑假进行高要求、 高强度、高难度的集中封闭式先进快速成图技能训练, 经 过多轮的培训、集中强化练习和辅导答疑, 选拔出优胜者 代表学校参加全国大学生先进成图技术及技能竞赛。

优秀的训练计划是取得优异成绩的有效保证。在学生 训练过程中, 教师们采取团队主导、二人主抓的总体原则, 团队教师都全心全意参与到计划的制定、修改、实施过程 中。另外, 学生作为计划实施的主体, 在训练过程中不时 发现问题, 对计划提出建议和意见, 充分发挥了学生的主 观能动性。经过近几年不断摸索与改进, 制定出了一套卓 有特色并行之有效的训练计划。

分步、渐入式训练计划可总结为广撒网、逐步收、先 行量、后突变。

•广撒网

机械制图任课教师对各班学生进行校内赛的尺规培训 并组织参加尺规绘图竞赛，几乎覆盖到所有学习制图课的 学生, 使学生绘图技能整体层次提高。

、逐步收

尺规竞赛优胜者进行三维建模集中讲座、培训; 选拔 建模优胜者; 再培训、再选拔; 逐渐缩小受众面, 根据学 生能力差异进行不同强度的训练。

- 先行量

训练各种类型零件、装配体, 并从数量角度训练达到 一定熟练度，保证遇图不慌，方法得当。

•后突变

摸索尺规绘图和三维建模的快速成图方式, 提高快速 成图技能, 达到由知识到技能的突变。

\section{2 探索 “尺规绘图” 先进成图技能提高训练模式}

尺规绘图是掌握先进成图技能的基础。在尺规绘图部 分, 主要以教师辅导的形式来促使学生形成良好的规范、 正确的结构分析方法，这对于整体先进成图技能的提升作 用极为关键。根据学生的反馈情况, 团队教师聚在一起找 错误、分类型、做总结, 并针对学生尺规绘图速度慢、图 面质量不高等问题, 提出一系列尺规专项训练方法, 使学 生做到心中有尺、眼中有尺、笔下有量。经过一定训练, 能够做到一笔画出定长直线、快速画圆弧、一笔画箭头, 练就了快速尺规绘图的扎实基本功。 


\section{3 研究三维建模快速成图 “专项”训练模式}

深入研究并总结出一套快速先进成图专项训练方法, 建立一系列包括快速零件建模专项、快速装配专项、快速 工程图尺寸标注专项、曲面专项等在内的快速成图训练模 块。其中零件建模专项和装配专项的训练在提高学生的快 速三维建模技能方面成效尤为显著。

\section{(1) 零件建模专项}

零件专项的训练, 主要通过建模前分析建模思路 (建 模步骤和建模方法) 来提高零件建模的速度, 并使建模更 有效。丰富了各种类型零件（支架类、座体类、盘盖类、 轴套类) 的练习, 并按照类型练习, 总结每种类型的建模 特点及其细节把握。

\section{(2) 装配专项}

装配问题在训练时凸显出来, 根据装配示意图进行快 速装配属于整个训练的难点、弱项。由于装配图见得少, 对装配关系不熟悉, 故装配耗时较长, 且不易把握住时间。 我们在装配专项训练中取得了大量的良好经验。

(1)夯实基础。装配图的表达方案, 必须按照工作位置 选择主视图, 有几条装配干线就一定有几个对应的基本视 图或剖视图。明确有内腔、有手柄、有螺栓连接组、有进 出油口、有齿轮啮合、有键连接等情况都如何表达, 夯实 基础方能进一步提高。

(2)归纳类型, 寻找共性。熟练掌握阀、泵、顶尖、减 速器等四大常见装配体类型, 总结每一类装配体的共性, 包括结构共性 (如夹紧机构、偏心结构、紧定螺钉、齿轮 齿条啮合结构等)、装配共性、视图表达共性等, 总结规律。 做过的类型要做到表达方案明确, 尺寸标注合理, 能够常 常在心中进行虚拟装配。

(3)扩展装配体类型, 熟悉装配图, 了解装配机理, 助 力装配。装配时, 按照只给装配示意图进行装配, 刻意忽 略有装配图的情况, 训练出学生对装配体装配关系、工作 原理的熟练度及举一反三的推理学习能力, 达到普通制图 课程课堂上的学生难以企及的高度。

(4)确定装配体复杂程度, 优化装配操作思路。装配体 简单、零件少时, 可一次性插入所有零件进行装配; 零件 多时, 应分批次插入零件, 并根据装配示意图对零件进行 大致的位置规划并分区域进行装配。

(5)建立全局意识。装配时, 综合考虑包括装配示意图、 明细栏中的零件名称和数量、包容件与被包容件 (或相配 合零件）的尺寸关系（尤其具有公差的轴、孔尺寸）等多 项内容进行零件或部件的功能分析, 最终实现装配。

(6)运用读装配图并拆读零件、建模、生成工程图的训 练方式, 深化对装配图的理解和认识。

这些行之有效的方法都在竞赛中发现或者得到应用和
提高, 丰富和充实了教学方法。通过深入分析学生在竞赛 及项目中体现出的对课程内容的理解及认识不足, 将其反 馈到教学中, 提高了教学质量。

3.4 建立竞争性 “协同学习” 的学习模式, 协调个体进步与 团队发展

“协同学习模式”, 是由教师指导的团队学习模式。在 课堂学习和竞赛训练中, 引入 “协同学习” 模式, 充分运 用 “团队协作” 小组学习模式的成员互补、不易疲劳、高 效、增强团队意识等优点, 尤其在课程和训练难点部分, 通过小组成员集思广益, 使学生体会 “团队协作” 的重要 性。

另外, 在高强度的训练过程中, 迫于竞赛需要, 不断 有人要被优化掉。在充满竞争的环境中, 学生的自主学习 热情被激发出来, 在项目团队的协作和交流中, 大大促进 了学生的思维能力、沟通能力、动手能力及合作精神, 其 综合素质得到培养, 成绩明显提高。

在充满竞争的 “协同学习” 小组中, 学生不仅要尽快 自身增长能力不被优化掉, 还要顾及团体赛的总体成绩提 高, 因此, 对学习与被学习、交流与合作都有了很好的体 会, 队员自身的创新设计能力和团队协作能力的培养上都 有明显的提高, 在社会人际交往与沟通能力上也得到了锻 炼。

\section{4. 工程制图课程连续性学习初见成效}

多年来, 在我们所组织或参与的校内先进成图竞技系 列活动中, 多数工科专业学生都对提高先进成图技能表现 出了很高的热情。近年来, 先后在机械、材料、信息等多 个专业学生中进行先进成图技能的讲座和培训, 为广大学 生演示二维尺规绘图技能和快速三维建模技能, 每次参加 人数都达二百多人, 对校先进成图竞赛优胜学生进行的高 水平先进成图技能集中封闭培训, 每届受众均达百余人。 这种 “以赛促学” 的形式受到广泛欢迎和好评。

我们所指导学生在工程图学教指委主办的全国大学生 先进成图及三维几何建模成绩突出。先后参加第三届至第 七届 “高教杯” 全国大学生先进成图技术与产品信息建模 创新大赛, 分获机械类团体二等奖 1 项, 连续获团体一等 奖 4 项, 个人全能一等奖二十余项, 并有多位指导教师荣 获 “优秀指导教师” 称号。

经过集中先进成图技能培训的学生, 已有越来越多的 人参与到高年级学科竞赛和创新项目中, 并担当了 “国家 大学生创新性试验计划” 和 “机械创新设计大赛” 等类似 科技活动的骨干力量。学生受益于先进成图技能在各方面 取得的优异成绩、奖励和表彰, 在广大学生中影响广泛。 
由于在提高学生先进成图技术技能方面的贡献突出, 有多 名制图教师获学校教学成果一等奖的表彰和奖励。

\section{5. 结束语}

“以赛促学” 方式是保持学生工程制图课程学习兴趣, 促进课程连续性学习的一种有效方式, 即通过引导学生以 参加高水平先进成图竞赛为契机, 积极参加工程制图课程 的讲座、校内培训、校内竞赛、国家竞赛等系列活动, 达 到课外连续应用制图知识, 提高先进成图技能的最终目的。

通过在较大范围内向学生介绍二维尺规绘图、快速三 维建模方法和技术, 引导其参与竞赛, 有效提高了学生运 用制图知识解决实际问题的实践技能和创新能力, 激发了 学生学习工程图学课程的热情, 为今后本课程的教学奠定 了良好的基础。

我们通过 “以赛促学” 方式促进了学生对工程制图课 程的连续性和扩展性学习, 使其制图知识转化为先进成图 技能, 尤其是快速三维建模能力, 望我们在这方面的探索 对高校基础课教师促进基础课程的连续性学习方面的研究 起到抛砖引玉的作用。

\section{参考文献(References)}

[1] J.P. Hu, "Reform on 3D CAD technology applied to mechanical drawing", Mechanical Management and Development, no. 1, pp. 176-177, 2011.

[2] H. Jiang and W.F. Ji, "Practice of teaching reform for the course of engineering graphics with the 3D drawing software solidworks", Journal of Engineering Graphics, no. 1, pp. 109-113, 2004.

[3] B.S. Tong, S.J. Yi and X.H. Xu, "Investigation and consideration of introducing 3D modeling into engineering graphics curriculum in China”, Journal of Engineering Graphics, no. 4, pp. 130-134, 2005.

[4] J.H. Wang, X.M. Li and L. Yang, et al, "A teaching reform of engineering drawing based on 3D modeling", Journal of Engineering Graphics, no. 6, pp. 123-126, 2008.

[5] S.X. Wang, G.F. Wang and Y.Y. Liu, et al, "Designers of multi-channel training model based on 3D CAD technology", Modern Manufacturing Engineering, no. 1, pp. 134-137, 2013.

[6] Y.P. Zeng, J.Q. Huang and S.F. Yin, "In manner of competition and textual research to promote mechanical drawing teaching", Mechanical Management and Development, vol. 24, no. 5, pp. 167-168, 2009. 